\title{
Curcumin's antioxidant effects on inflammatory diseases
}

\section{Halime SELEN', Veysel ÇOMAKLI}

Cite this article as:

Selen, H., Çomakl1, V. (2021). Curcumin's antioxidant effects on inflammatory disease. Food and Health, 7(1), 45-53. https://doi.org/10.3153/FH21006

Ağrı Ibrahim Cecen University, School of Health, Department of Nutrition and Dietetics, Ağrı, Turkey

ORCID IDs of the authors:

H.S. 0000-0002-3705-0875

V.Ç. 0000-0003-2109-6702

Submitted: 24.07 .2020

Revision requested: 15.09 .2020

Last revision received: 17.09 .2020

Accepted: 18.09 .2020

Published online: 03.12 .2020

Correspondence: Halime SELEN

E-mail: halimeselen@gmail.com

\begin{abstract}
There are similar inflammatory reasons behind non-contagious chronic diseases. The prevalence of these diseases increases everyday both in our country and around the world. That's why scientists have begun looking for strong antioxidants that could help prevent and treat such inflammatory diseases. Curcumin is one of those antioxidants. Curcumin is one of the components of turmeric, which belongs to the ginger family. Many studies showed that the curcuminoids in turmeric can be used to prevent and treat cardiovascular, autoimmune and endocrine diseases, cancer as well as various inflammatory diseases. With this study, we aim to interpret these recent studies conducted with curcumin.
\end{abstract}

Keywords: Antioxidant, Curcumin, Health, Inflammatory Diseases

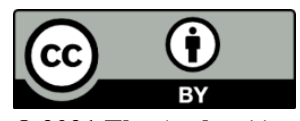

(c) 2021 The Author(s)

Available online at

http://jfhs.scientificwebjournals.com 


\section{Introduction}

Curcumin is a component derived from turmeric, which is used to add flavor and a yellowish color to dishes. First used by ancient Greeks, curcumin is used as a spice mostly in India and as a traditional medicine ingredient in Southeast Asia and China (Nahar et al., 2015). Curcumin, used as E100 as a food additive, can be found in mustards, cheese, canned fish, butter, pastry, and other many similar processed food (Chin et al., 2013). Curcumin is one of the main ingredients of turmeric and has anti-carcinogenic, antioxidant and anti-inflammatory effects. Thanks to these properties, curcumin is known to be effective in the protection against and treatment of many inflammatory diseases (Kumar and Sharma, 2015).

\section{Antioxidant Mechanism of Action of Curcumin}

Oxygen consumption during cell growth leads to the production of free radical oxygen intermediates as a result of a series of reactions, such as superoxide anion radicals, hydroxyl radicals, and hydrogen peroxide $\left(\mathrm{H}_{2} \mathrm{O}_{2}\right)$. These radicals cause damage to biomolecules that play a critical role in maintaining life on Earth, including proteins, lipids, nucleic acids, and carbohydrates. Reactive oxygen species (ROS) lead to the development of various diseases, if they are not effectively excreted by cellular components. It is a known fact that ROS is involved in the pathophysiology of many diseases (Neeraj et al., 2008; Aksoy, 2018). Antioxidant defenses, including antioxidant enzymes or functional food ingredients, are needed to eliminate or repair these harmful effects of ROS. Functional foods, also known as antioxidant compounds, have important functions in the body such as preventing the mechanisms of free radical formation and removing the formed radicals (Ak and Gülçin, 2008). Curcumin, one of these functional foods, has been reported to be able to eliminate the harmful effects of metal ions that contribute to free radical formation by chelating them (Figure 1) and to increase antioxidant capacity by transferring electrons to the produced free radicals, or by creating a mechanism of inhibitor and activator action on the enzyme activity that plays an important role in metabolism (Ak and Gülçin, 2008; Asouri et al., 2013; Tanvir et al., 2017).<smiles>COc1cc(C=C/C(O)=C/C(=O)/C=C/c2ccc(O)c(OC)c2)ccc1O</smiles>

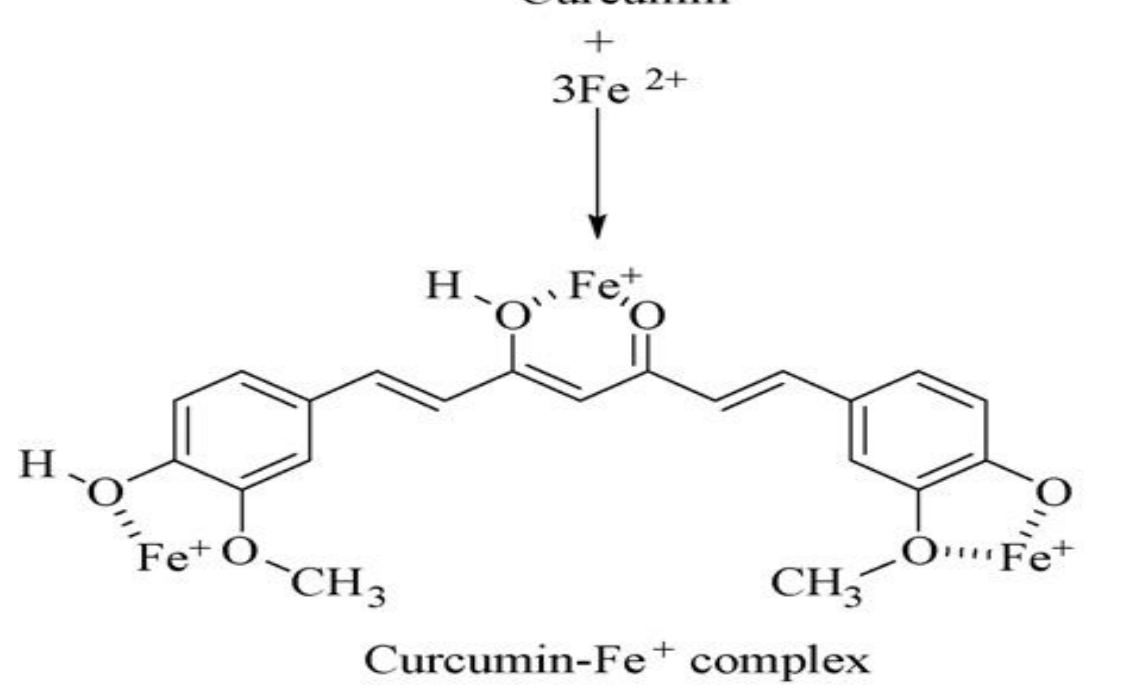

Figure 1. Proposal reaction of iron ions chelated by curcumin (Ak and Gülçin, 2008) 
There are studies that support this information. For instance, in a study in which Drosophila Melanogaster was exposed to $\mathrm{Al}^{3+}$ metal ion, it has been reported that antioxidant parameters such as catalase, glutathione S-transferase and glutathione decreased and free radical precursors such as $\mathrm{NO}$ and $\mathrm{H}_{2} \mathrm{O}_{2}$ increased. The effect of this oxidative damage caused by $\mathrm{Al}^{3+}$ ion was reported to be eliminated by the curcumin molecule depending on the dose (Oyetayo et al., 2020).

Curcumin has been further shown to have very strong antiinflammatory effects in addition to its antioxidant properties. In the literature, pro-inflammatory cytokines have been shown to form the basis for the development of non-communicable chronic diseases, including diabetes, pancreatic cell disorders, Alzheimer's disease, arthritis, cardiovascular diseases, intestinal diseases, polycystic ovary syndrome, and lipid disorders (Laveti et al., 2013). The phytochemical and polyphenol properties of curcumin inhibit the structures causing inflammation in the body, such as TNF- $\alpha$, IL-1 $\beta$, IL-6, MCP-1, Prostaglandin $E_{2}$, Nuclear Factor Kappa Beta (NFkB)' Cyclooxygenase-2 ( $\left.\mathrm{COX}_{2}\right)$, and 5-Lipoxygenase (5LOX). In contrast, curcumin has an activating or enhancing effect on cellular signal molecules such as interleukin, chemokine, cytokine, growth factors, enzymes, transcription factors, Nrf2, $\beta$-catenin, signal transduction and transcription (STAT), factors of the O class (FOXOs), and protein kinases (Figure 2).

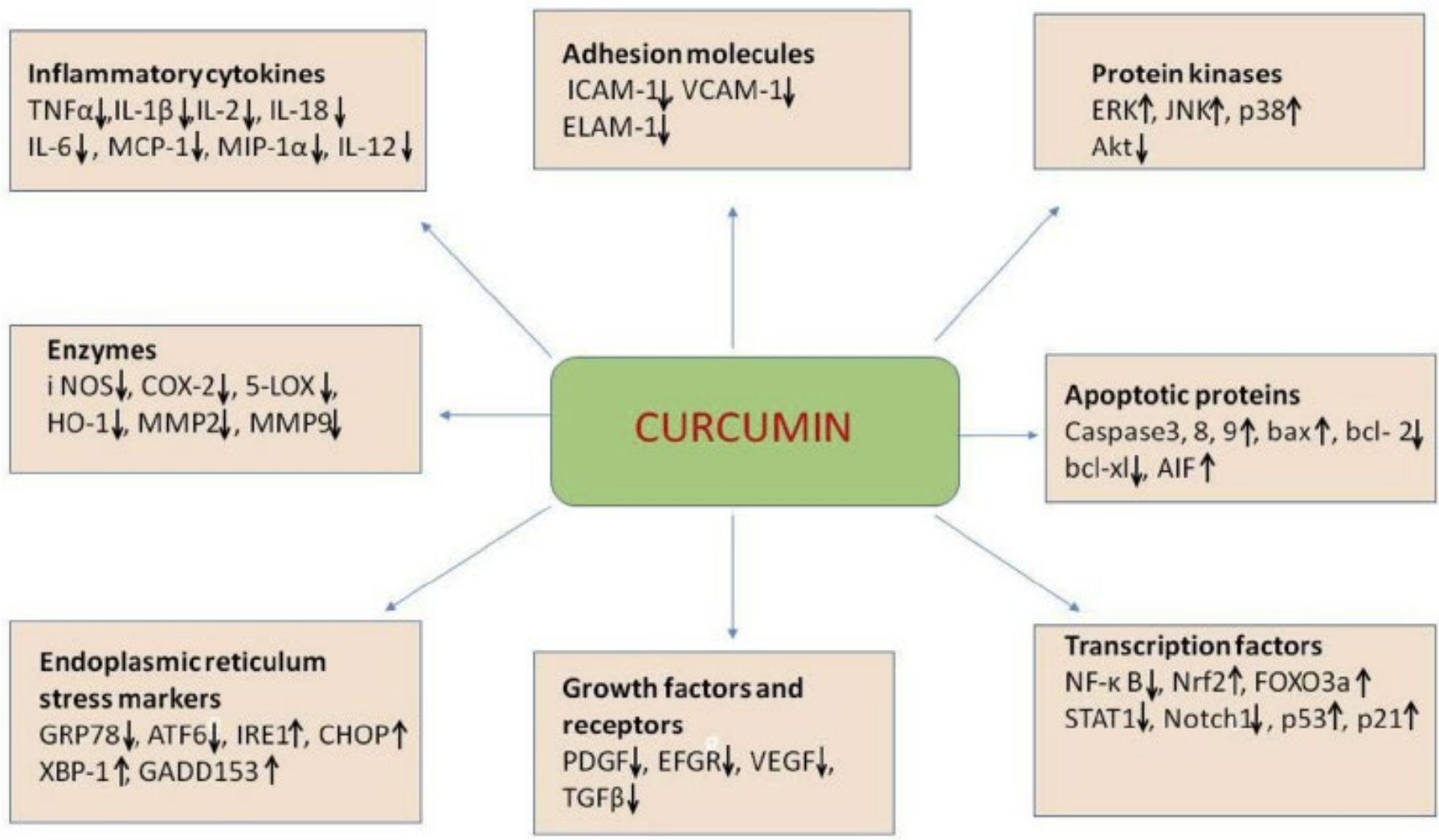

Figure 2. Molecular targets of curcumin (Ghosh et al., 2015) 
Moreover, curcumin blocks the cell growth cycles in cancer cells, and reduces free radicals and inflammation, both of which can lead to cancer-causing cell mutations (Chen et al., 2010). Curcumin, a polyphenol derivative, has been reported to have positive effects on learning and verbal memory and to have a protective and therapeutic effect on health problems such as Alzheimer's and Parkinson's disease (Harish et al., 2010).

\section{Literature Search}

In a study the researchers examined the effects of curcumin on colon histology. They used azoxymethane to grow tumors in one group of rats, separated them as control and study group. Then they gave control group certain doses of curcumin along with their feed. The excrement of the rats were collected once in every four weeks for microbiological analysis and the rats were observed for 14 weeks. At the end of the study, it was seen that the rats that were given feed with the curcumin additive had higher survival rates, that the weight and length of their colons reduced and the tumor burden reduced by $0.5 \%$. In study rats, curcumin increased the microbial richness, prevented age-related reduction in alpha diversity, increased the relative abundance of Lactobacillales (by genus Lactobacillus) and reduced the order of Coriobacteriales (Actinobacteria phylum). In other words, curcumin inhibited the genes related to inflammation, reduced or completely removed the colonic tumor burden (McFadden et al., 2015).

In another study, 20 female Wistar rats (20 months old) were separated as control and study groups. The study group rats were given curcumin extract for 12 days $(300 \mathrm{mg} / \mathrm{kg})$ in corn oil with oral gavage. After 24 hours heart tissues are taken ander anesthesia, and protein carbonyl (PC), Malondialdehyde (MDA) and Glutathione (GSH) levels were checked. GSH level of rats that were fed curcumin supplement, was found to be significantly higher compared to the study group $(p<0.05)$. PC and MDA levels were found to be low, albeit not significantly $(p>0.05)$. In other words, curcumin protected the heart issue of these old female rats from oxidative damage and strengthened the antioxidants defense system (Belviranl1 et al., 2012).

Since prostate cancer is the most diagnosed cancer and among the biggest cause of death in the males in the USA, many studies are conducted to understand the molecular basis of the progression of this cancer. Also various efforts are underway to achieve early diagnosis and to develop new treatment strategies for the disease. Protein kinase D1 (PKD1), is a multi-functional kinase that is produced in high amounts in a normal prostate. The reduction of PKD1 expression is associated with the progression of prostate cancer (Jaggi et al.,
2007). It was shown that curcumin, an active component of turmeric, activates PDK1, which in turn blocks the transcription activity of the nuclear $\beta$-katenin in prostate cancer cells and increases $\beta$-katenin signal levels. In this study, the rats with prostate cancer were divided into study and control groups and the study group were given intratumoral injection of curcumin at certain times and dosages. It was seen that compared to the control group, the tumor growth in the study group which were given curcumin additive, was inhibited 2 times more. It was explained that this effect became possible through improved membrane localization of $\beta$-katenin and the reduction of cofilin activity downstream of PDK1 (Sundram et al., 2012).

In another study, the researchers tried to understand the effect of curcumin and Kaempferol on acute pancreatitis, which was produced in rats using L-Arginine. 38 male rats were separated into 6 equal groups and the first group (control group) was administered serum physiologic (SF-NaCl) through Intraperitoneal injection (IP), the second group was administered Larginine through IP and the third group was administered dimethyl sulfoxide (DMSO) through IP, the fourth group L-Arginine + Curcumine through IP, the fifth group L-arginine + kaempferol (flavanol) through IP and the sixth group was administered L-arginine+curcumin+kaempgerol through IP. In acute pancreatitis, although it is not meaningful, it was seen that antioxidant system indicators in treatment groups were higher clinically and the oxidative stress indicators were lower. It was also seen that cytoskeleton that was administered curcumin and kaempferol antioxidant, were preserved better compared to other groups (Turgut, 2019).

In a study was conducted to understand if the curcumin, a phytochemical compound, was effective on the preservation of remission in patients with ulcerative colitis (UC). 50 patients with active, mild and moderate UC was included in the study using the simple clinical colitis activity index (SCCAI). Patients that did not respond to non-steroidal anti-inflammatory drug (NSAID) treatment, were divided into random groups and for four weeks, curcumin tables administered to 26 patients ( $3 \mathrm{~g} /$ day) and an identical placebo was administered to 24 patients. After the study, it was seen that $14 \%$ of the curcumin administered patients clinically recovered and none of the patients in placebo group recovered. 17 patients in curcumin group and 3 patients in placebo group, achieved clinical response with 3-point reduction in their SCCAI scores. As a conclusion, in the induction of clinic and endoscopic remission, the addition of curcumin in UC treatment, was found more successful than the combination of placebo and mesalamine (Lang et al., 2015). 
Another study sought to determine the effect of curcumin taken with a high-fat diet, on the antioxidant and oxidant balance in the testicles. To this end, rats were divided into four groups. First group was fed with a normal diet where the $10 \%$ of the energy came from fats, the second group with a high fat diet (HFD), where the $60 \%$ of the energy came from fats, the third group with a HFD where curcumin was added in the feed $(1 \mathrm{~g} / 1 \mathrm{~kg})$, and the fourth group with a normal diet with a curcumin addition $(1 \mathrm{~g} / 1 \mathrm{~kg})$. At the end of the study, reactive oxygen sorts (ROS), malondialdehyde (MDA), Glutathione (GSH), Glutathione peroxidase (GPx), Superoxide dismutase (SOD) and glutathione transferase (GST) activities were measured. HFD application increased the MDA levels and decreased the GSH levels in the testicles. Curcumin given together with HFD, decreased the MDA levels which rose due to HFD and increased the GSH levels and GST activities. However, curcumin addition to normal diet did not affect the antioxidant and oxidant indicators. In ROS, SOD and GPx values, no significant differences were observed between the groups. To conclude, it was shown that curcumin addition administered with a HFD, could preserve the antioxidant and oxidant levels in the testicles (Seyithanoğlu et al., 2020).

In a study conducted with overweight and obese female with high blood lipid profiles, the effect of the turmeric on weight loss and blood lipids was examined. Accordingly 70 females were divided into study and control groups and the control group were administered medical diet for loss weight of 0.5 $1 \mathrm{~kg}$ per week and the study group was given $4 \mathrm{~g}$ of curcumin everyday in addition to the above. Biochemical parameters were measured before and after the study which lasted 8 weeks. Although the female in the study group lost more weight, these values were insignificant. Similarly, there was drop in the fasting blood glucose, total cholesterol, high density lipoprotein (HDL)-low density lipoprotein (LDL) cholesterol, triglyceride but it was insignificant. Also, the effect of curcumin administered in addition to diets prescribed by dietitians for individuals who had high blood lipid profile and who were overweight and obese, was not found statistically significant. However, considering individual differences and that the period was limited to 8 weeks, it can be suggested that similar studies can be repeated over longer periods (Atakan, 2017).

In a study, conducted to reveal if curcumin could be a treatment for Psoriasis Area and Severity Index (PASI), 63 patients with mild and moderate Psoriasis Vulgaris (PASI $<10$ ), and who are administered topical steroids, were randomly divided into two groups. For 12 weeks, one group was given a lecithin-based curcumin supplement (Meriva) of 2 grams next to local drug therapy, while the other group was given a placebo along with local drug therapy. Both groups saw significant drop in PASI levels but the reduction in IL-22 level was found significant in the group that was administered Meriva in addition to local steroids, compared to placebo group $(\mathrm{p}<0.001)$. It was shown that curcumin was effective as an adjacent treatment for Psoriasis Vulgaris and significantly reduced the IL-22 serum levels (Antiga et al., 2015).

In a study conducted with prediabetic population, the researchers wanted to determine the effect of the curcumin in delaying the development of type 2 diabetes mellitus (DM). They randomly divided 240 volunteers in two groups. For 9 months, one of the groups were administered curcumin capsules of $1500 \mathrm{mg}$, and the other group was administered equal amount of placebo. At the 3rd, 6th and 9th months, the participants were monitored to determine the number of patients that developed type $2 \mathrm{DM}$, the changes in $\beta$-cell functions (homeostasis model evaluation [HOMA]-b, C-peptit and proinsulin / insulin), insulin resistance (HOMA-IR), anti-inflammatory cytokine (adiponektin) and other parameters. After 9 months, $16.4 \%$ of the participants in placebo group were diagnosed with type $2 \mathrm{DM}$, but no patients that were treated with curcumin were diagnosed with type 2 DM. In addition, the group treated with curcumin, had higher HOMA-b, lower $\mathrm{C}$-peptide and better general functioning of $\beta$ cells. The group treated with curcumin, showed lower HOMA-IR levels and higher adinopektine compared to placebo group. Therefore, it was shown that curcumin administration could help prediabetic people (Chuengsamarn et al., 2012).

Another study was designed to determine if curcuminoids prevented myocardial infarction (MI) after coronary arterial bypass grafting (CABG), based on previous studies that showed curcuminoids reduced preinflammatory cytokines during cardiopulmonary bypass surgery and that it reduced the formation of cardiomiotic apoptosis after cardiac ischemic damage (Yeh et al., 2005). 121 patients that were subjected to CABG participated in the study. One group was given $4 \mathrm{~g} /$ day curcuminoid starting three days before the planned surgery and other group was given same amount of placebo and the administration continued until five days after the surgery. The MI prevalence in the hospital reduced to $30.0 \%$ in the placebo group and to $13.1 \%$ in curcuminoid group. Postoperative C-reactive protein, malondialdehyde and $\mathrm{N}$ terminal pro-B type natriuretic peptide levels were seen to be lower in curcuminoid group compared to placebo groups (Wongcharoen et al., 2012).

In a study, 65 patients with metabolic syndrome was randomly divided into study and control groups. For 12 weeks, 33 people were administered $630 \mathrm{mg}$ curcumin capsules, and 32 people were administered placebo capsules three times a day. 12 weeks after curcumin consumption, there was increase in HDL-C levels, and drop in LDL-C and triglyceride levels. Curcumin consumption led to reduced cholesterol in 
males and increased HDL-C in females and in both groups, it reduced T-Chol/HDL-C rates. Consumption of $1890 \mathrm{mg} /$ day curcumin for 12 weeks decreased lipids but was not found significantly effective in treating weight and glucose homeostasis in metabolic syndrome patients. Daily consumption of curcumin can be an alternative option to balance the relevant parameters in metabolic syndrome patients (Yang et al., 2014). In an article where various studies were discussed, it was stated that curcumin had an anti-obesity effect (Mohamed et al., 2014).

In a study designed to determine the effect of ginger supplement on non-alcoholic fatty liver patients, study group was administered $2 \mathrm{~g}$ /day ginger supplement in addition to their diets which consisted of $52-55 \%$ carbohydrates, $30 \%$ fat, $15-$ $18 \%$ protein and 20-30 g/day fiber. The groups that was administered ginger, showed significant drop in inflammatory cytokines, and parameters like liver enzymes $\gamma$-glutamyl transferase (GGT), alanine aminotransferase (ALT) (Rahimlou et al., 2016).

In a randomized study designed to determine the effect of curcumin on experimental ischemic and ischemic / reperfusion $(\mathrm{I} / \mathrm{R})$ damage in rat ovaries, 48 female wistaria rats were used. In groups that were administered curcumin, a significant reduction in the average levels of oxidant indicators of ovarian tissues and their histopathological scores, was observed (Sak et al., 2013).

Polycystic ovary syndrome (PCOS) is a very prevalent syndrome in female of reproductive age. It is often characterized by obesity, insulin resistance, hyperandrogenemia, and hirsutism (Deniz et al., 2012). In a study where curcumin supplements effect on PCOS, 72 adult female wistar rats were used. They were divided into groups of study group (healthy), PCOS group and curcumin group. After 60 days of application, ovaries were collected and analyzed for histological and Immuno-Histochemical evaluations. In curcumin group, number of corpus luteum (CL) increased, and IL-6 and C-reactive protein (CRP) inflammatory markers significantly dropped. While TNF- $\alpha$ expression and follicular fluid of follicles and ovary cysts in PCOS group was higher compared to control group, these expressions reduced in ovaries treated with curcumin. This study is indicative of curcumin's antiinflammatory and antioxidant effects on PCOS (Mohammadi et al., 2017).

In a study that examined the effects of curcumin on body weight, glisemic control and serum lipids, 18-40 year old females with 60 PCOS, were divided into curcumin $(n=30)$ and placebo $(n=30)$ groups. The curcumin group was administered $500 \mathrm{mg} /$ day curcumin for 12 weeks and the placebo group was administered same amount of placebo. Parameters were measured in the beginning of the study and after 12 weeks of application and there has been a significant improvement in their level in body mass index (BMI), serum insulin, insulin resistance, insulin sensitivity, peroxisome proliferator-activated receptor gamma (PPAR- $\gamma$ ), low-density lipoprotein receptor (LDLR), HDL, LDL and total cholesterol levels (Jamilian et al., 2020).

Many studies were conducted on humans and animals where it was shown that curcumin had positive effects on rheumatoid arthritis. 45 patients with rheumatoid arthritis were divided into 3 groups. The first group was administered 500 $\mathrm{mg}$ /day curcumin, the second was administered diclofenac sodium $50 \mathrm{mg} /$ day which is a medication used for the treatment of the said disease and the third group was given a combination of the two. There was no significant difference between the groups according to the Rheumatoid Arthritis Disease Activity Score (DAS-28) and the criteria of the American College of Radiology (ACR), nevertheless, the groups that were administered curcumin, showed the best improvement. The serum CRP levels showed significant change only in the curcumin group, but no significant changes were observed in other chemical and hematologic parameters (Chandran and Goel, 2012). Similarly, in a study conducted with Wistar rats with rheumatoid arthritis, it was reported that curcumin inhibited the redness and eudema in ankles and joints of rats and also inhibited the increasing levels of pro inflammatory cytokines like IL-1 $\beta$, TNF-a, MMP-1 and MMP-3 (Dai et al., 2016).

\section{Conclusion}

There are similar inflammatory reasons behind non-contagious chronic diseases. The prevalence of these diseases increases everyday both in our country and around the world. That's why scientists have begun looking for strong antioxidants that could help prevent and treat such inflammatory diseases. Curcumin is one of those antioxidants. Since no toxic effects of curcumin was determined in studies, it has been used for treatment of the aforementioned diseases for a long time.

Due to its low cost and reliability, turmeric, of which curcu$\mathrm{min}$ is the main ingredient, is considered promising in the prevention and treatment of diseases. Studies suggest that consumption of $1-5 \mathrm{~g}$ of turmeric, which equals to $150 \mathrm{mg}$ curcumin, does not create any toxic effect (Sharma et al., 2005); however the joint report of World Health Organization and United Nations Food and Agriculture Organization states that the side effects of curcumin should be studied and the maximum daily dosage must be $1 \mathrm{mg} / \mathrm{kg}$ (WHO, 2000). 
We believe that in the face of changing life conditions, unhealthy diets and the life style brought about by sedentary life, having turmeric in our daily diet will prove preventive against diseases.

\section{Compliance with Ethical Standard}

Conflict of interests: The authors declare that for this article they have no actual, potential or perceived the conflict of interests.

Ethics committee approval: The authors declare that this study does not require ethical permission.

Funding disclosure: -

Acknowledgments: -

Disclosure: -

\section{References}

Ak, T., Gülçin, İ. (2008). Antioxidant and radical scavenging properties of curcumin. Chemico-Biological Interactions, $174,27-37$.

https://doi.org/10.1016/j.cbi.2008.05.003

Aksoy, A. (2018). Determination of the DNA damage levels in patients with chronic renal failure using 8-hydroxy-2'deoxyguanosine biomarker. Fresenius Environmental Bulletin, 27(12a), 9308-9314.

Antiga, E., Bonciolini, V., Volpi, W., Del Bianco, E., Caproni, M. (2015). Oral curcumin (meriva) is effective as an adjuvant treatment and is able to reduce IL-22 serum levels in patients with Psoriasis vulgaris. BioMed Research International, 1-7.

https://doi.org/10.1155/2015/283634

Asouri, M., Ataee, R., Ahmadi, A.A., Amini, A., Rezaei Moshaei, M. (2013). Antioxidant and free radical scavenging activities of curcumin. Asian Journal of Chemistry, 25(13), 7593-7595.

https://doi.org/10.14233/ajchem.2013.15308

Atakan, A. (2017). Kilolu ve obez bireylerde zerdeçal tüketiminin ağırlık kaybı ve kan lipid düzeyleri üzerindeki etkisinin değerlendirilmesi. Doğu Akdeniz Üniversitesi, Lisansüstü Eğitim, Öğretim ve Araştırma Enstitüsü, Yüksek Lisans Tezi, Gazimağusa.
Belviranlı, M., Okudan, N., Nurullahoğlu, Atalık. K.E. (2012). Yaşlı sıçanlarda kurkumin takviyesinin kalp dokusunun oksidan/antioksidan durumu üzerine etkileri. Genel Tip Dergisi, 22(2), 61-66.

Chandran, B., Goel, A. (2012). A randomized, pilot study to assess the efficacy and safety of curcumin in patients with active rheumatoid arthritis. Phytotherapy Research, 26(11), 1719-1725.

https://doi.org/10.1002/ptr.4639

Chen, Q.Y., Lu, G.H., Wu, Y.Q., Zheng, Y., Xu, K., Wu, L.J., Jiang, Z.Y., Feng, R., Zhou, J.Y. (2010). Curcumin induces mitochondria pathway mediated cell apoptosis in A549 lung adenocarcinoma cells. Oncology Reports, 23(5), 1285-1292.

https://doi.org/10.3892/or 00000762

Chin, D., Huebbe, P., Pallauf, K., Rimbach, G. (2013). Neuroprotective properties of curcumin in Alzheimer's diseasemerits and limitations. Current Medicinal Chemistry, 20(32), 3955-3985.

https://doi.org/10.2174/09298673113209990210

Chuengsamarn, S., Rattanamongkolgul, S., Luechapudiporn, R., Phisalaphong, C., Jirawatnotal, S. (2012). Curcumin extract for prevention of type 2 diabetes. Diabetes Care, 35, 2121-2127.

https://doi.org/10.2337/dc12-0116

Dai, C., Li, D., Gong, L., Xiao, X., Tang, S. (2016). Curcumin ameliorates furazolidone-induced DNA damage and apoptosis in human hepatocyte L02 cells by inhibiting ROS production and mitochondrial pathway. Molecules, 21(8), E1061.

https://doi.org/10.3390/molecules21081061

Deniz, R., Gürateş, B., Aydın, S., Çelik, H., Sahin, İ., Baykuş, Y., Çatak, Z., Aksoy, A., Çitil, C., Güngör, S. (2012). Nesfatin-1 and other hormone alterations in polycystic ovary syndrome. Endocrine, 42, 694-699.

https://doi.org/10.1007/s12020-012-9638-7

Ghosh, S., Banerjee, S., Sil, P.C. (2015). The beneficial role of curcumin on inflammation, diabetes and neurodegenerative disease: A recent update. Food Chemical Toxicology, 83, 111-124.

https://doi.org/10.1016/j.fct.2015.05.022

Harish, G., Venkateshappa, C., Mythri, R.B., Dubey, S.K., Mishra, K., Singh, N., Vali, S., Bharath, M.M. 
(2010). Bioconjugates of curcumin display improved protection against glutathione depletion mediated oxidative stress in a dopaminergic neuronal cell line: Implications for Parkinson's disease. Bioorganic \& Medicinal Chemistry, 18(7), 2631-2638.

https://doi.org/10.1016/j.bmc.2010.02.029

Jaggi, M., Du, C., Zhang, W., Balaji, K.C. (2007). Protein kinase D1: A protein of emerging translational interest. Frontiers in Bioscience, 12, 3757-3767.

https://doi.org/10.2741/2349

Jamilian, M., Foroozanfard, F., Kavossian, E., Aghadavod, E., Shafabakhsh, R., Hoseini, A., Asemi, Z. (2020). Effects of curcumin on body weight, glycemic control and serum lipids in women with polycystic ovary syndrome: A randomized, double-blind, placebo-controlled trial. European Society for Clinical Nutrition and Metabolism, 36, 128-133. https://doi.org/10.1016/j.clnesp.2020.01.005

Kumar, A., Sharma, N. (2015). Comparative efficacy of piperine and curcumin in deltamethrin induced splenic apoptosis and altered immune functions. Pesticide Biochemistry and Physiology, 119(1), 16-27.

https://doi.org/10.1016/j.pestbp.2015.03.003

Lang, A., Salomon, N., Wu, J.C., Kopylov, U., Lahat, A., Har-Noy, O., Ching, J.Y., Cheong, P.K., Avidan, B., Gamus, D., Kaimakliotis, I., Eliakim, R., Ng, S.C., Ben-Horin, S. (2015). Curcumin in combination with mesalamine induces remission in patients with mild-to-moderate ulcerative colitis in a randomized controlled trial. Clinical Gastroenterology Hepatology, 13(8), 1444-1449.

https://doi.org/10.1016/j.cgh.2015.02.019

Laveti, D., Kumar, M., Hemalatha, R., Sistla, R., Naidu, V.G., Talla, V., Verma, V., Kaur, N., Nagpal, R. (2013). Anti-inflammatory treatments for chronic diseases: A review. Inflammation \& Allergy - Drug Targets, 12(5), 349-361. https://doi.org/10.2174/18715281113129990053

McFadden, R.T., Larmonier, C.B., Shehab, K.W., Midura-Kiela, M., Ramalingam, R., Harrison, C.A., Besselsen, D.G., Chase, J.H., Caporaso, J.G., Jobin, C., Ghishan, F.K., Kiela, P.R. (2015). The role of curcumin in modulating colonic microbiota during colitis and colon cancer prevention. Inflammatory Bowel Diseases, 21(11), 24832494.

https://doi.org/10.1097/MIB.0000000000000522
Mohamed, G.A., Ibrahim, S.R.M., Elkhayat, E.S., El Dine, R.S. (2014). Natural anti-obesity agents. Bulletin of Faculty Pharmaciy Cairo University, 52, 269-284.

https://doi.org/10.1016/j.bfopcu.2014.05.001

Mohammadi, S., Kayedpoor, P., Karimzadeh-Bardei, L., Nabiuni, M. (2017). The effect of curcumin on TNF- $\alpha$, IL-6 and CRP expression in a model of polycystic ovary syndrome as an inflammation state. Journal of Reproduction \& Infertility, 18(4), 352-360.

Nahar, P.P., Slitt, A.L., Seeram, N.P. (2015). Anti-inflammatory effects of novel standardized solid lipid curcumin formulations. Journal of Medicinal Food, 18(7), 786-792.

https://doi.org/10.1089/jmf.2014.0053

Neeraj, J.P., Singh S, Singh J. (2008). Role of free radicals and antioxidants in human health and disease. International Journal of Current Research and Review, 5(19), 14-22.

Oyetayo, B.O., Amos, O., Abolaji, A.O., Fasae, K.D., Aderibigbe, A. (2020). Ameliorative role of diets fortified with curcumin in a Drosophila Melanogaster model of aluminum chloride-induced neurotoxicity. Journal of Functional Foods, 71, 1-7.

https://doi.org/10.1016/j.jff.2020.104035

Rahimlou, M., Yari, Z., Hekmatdoost, A., Alavian, S.M., Keshavarz, S.A. (2016). Ginger supplementation in nonalcoholic fatty liver disease: A randomized, double-blind, placebo-controlled pilot study. Hepatitis Monthyl, 16(1), 1-5. https://doi.org/10.5812/hepatmon.34897

Sak, M.E., Soydinc, H.E., Sak, S., Evsen, M.S., Alabalik, U., Akdemir, F., Gul, T. (2013). The protective effect of curcumin on ischemia-reperfusion injury in rat ovary. International Journal of Surgery, 11(9), 967-970.

https://doi.org/10.1016/j.ijsu.2013.06.007

Seyithanoğlu, M., Tanrıkulu Küçük, S., Öner İyidoğan, Y., Koçak, H., Mikailova, P., Aydın, A.F. (2020). Kurkumin uygulamasının yüksek yağlı diyetle beslenen sıçanların testis dokusunda oksidanantioksidan sistem üzerine etkisi. $\dot{I}_{s-}$ tanbul Tıp Fakültesi Dergisi, 83(3), 247-253.

https://doi.org/10.26650/IUITFD.2019.0049

Sharma, R.A., Gescher, A.J., Steward, W.P. (2005). Curcumin: The story so far. European Journal of Cancer, 41(3), 1955-1968.

https://doi.org/10.1016/j.ejca.2005.05.009 
Sundram, V., Chauhan, S.C., Ebeling, M., Jaggi, M. (2012). Curcumin attenuates $\beta$-catenin signaling in prostate cancer cells through activation of protein kinase D1. PLoS One, 7(4), 1-13.

https://doi.org/10.1371/journal.pone.0035368

Tanvir, E.M., Hossen, M.S., Hossain, M.F., Afroz, R., Hua Gan, S., Khalil, M.I., Karim, N. (2017). Antioxidant properties of popular turmeric (curcuma longa) varieties from Bangladesh. Journal of Food Quality, 8471785, 1-8.

https://doi.org/10.1155/2017/8471785

Turgut, M. (2019). Deneysel akut pankretit'te kaempferol ve kurkumin'in etkilerinin araştırılması. Pamukkale Üniversitesi, Tıp Fakültesi, Uzmanlık Tezi, Denizli.

Wongcharoen, W., Jai-Aue, S., Phrommintikul, A., Nawarawong, W., Woragidpoonpol, S., Tepsuwan, T., Sukonthasarn, A., Apaijai, N., Chattpakorn, N. (2012). Effects of curcuminoids on frequency of acute myocardial infarction after coronary artery bypass grafting. American Journal of Cardiology, 110, 40-44.

https://doi.org/10.1016/j.amjcard.2012.02.043
WHO (2000). Evaluation of certain food additives: Fifty-first report of the joint FAO/WHO expert committee on food additives. World Health Organization \& Food and Agriculture Organization of The United Nations.

Yang, Y.S., Su, Y.F., Yang, H.W., Lee, Y.H., Chou, J.I., Ueng, K.C. (2014). Lipid-lowering effects of curcumin in patients with metabolic syndrome: A randomized, double-blind, placebo-controlled trial. Phytotheraop Research, 28, 17701777.

https://doi.org/10.1002/ptr.5197

Yeh, C.H., Chen, T.P., Wu, Y.C., Lin, Y.M., Jing Lin, P. (2005). Inhibition of NFKB activation with curcumin attenuates plasma inflammatory cytokines surge and cardiomyocytic apoptosis following cardiac ischemia/reperfusion. Journal of Surgical Research, 125(1), 109-116.

https://doi.org/10.1016/j.jss.2004.11.009 